\title{
Study on Hydrodynamic Water Quality Model and Dynamic Environmental Capacity of Qingyi River Basin
}

\author{
Yanpeng Wang, Li Wang, and Kuan Zhang
}

\begin{abstract}
Due to the change of natural conditions, the water environmental capacity presenting time dynamic characteristics. In this study, the Xuchang section of Qingyi River Basin was taken as the research object, The EFDC model was adopted, COD and ammonia nitrogen as the main pollution factor, the dynamic water environmental capacity was studied. By constructing a one-dimensional hydrodynamic water quality model of Qinghe River Basin, Calculate of Water Environmental Capacity of Main Tributaries in Qingyi River Basin. The result shows that the environmental capacity of main stream is occupying the most proportion in the whole river basin, Qingni River is much more than others in the main stream. In order to control the water quality of Qingyi River Basin and control the total amount of pollutants in Qingyi River Basin, we established the water quality and water quality model in Qingyi River Basin.
\end{abstract}

Index Terms-Qingyi river, EFDC, dynamic environmental capacity.

\section{INTRODUCTION}

Water is the primary basis to maintain the ecological environment for sustainable development, with the development of industrialization and the new urbanization process, the river basin water environment is facing new challenges. Some tributaries are polluted seriously and water connectivity is poor which are affecting human health and ecological security. It is urgent to focus on river basin water quality target management, effectively forecast the change trend of water quality in the river basin, explore the water quality target management mode of the river basin and improve the Scientific Management Level of Water Pollution Prevention and Control [1]-[3].

Qingyi River belongs to Shaying River system in the Huaihe River Basin, which is one of the most important tributaries of the Shaying River. It is a very important water body applied in flood control, drainage, sewage and landscape of Xuchang city. This study on the dynamic variation of the hydrodynamics in the Qingyi River Basin is carried out to predict the water quality changes and provide the basic support for the basin water environment management.

EFDC model has been widely used in the United States,

Manuscript received December 5, 2016; revised February 6, 2017. This work was supported by Major Science and Technology Program for Water Pollution Control and Treatment (2015ZX07210-002-005, PR China).

Yanpeng Wang and Kuan Zhang are with Research Center for Environmental Policy Planning and Assessment of Zhengzhou University, Henan, PR China (e-mail: wangyanpeng08@163.com, zhkjia@163.com).

Li Wang is with Zhengzhou University, Henan, PR China (e-mail: xiawangli@zzu.edu.cn). other countries and regions because of its advanced and reliability, the application research of EFDC model is being carried out in China in recently years. Yihui Chen Simulated the water dynamics and water quality in Dianchi Lake. The results of hydrodynamic simulation of the model are acceptable and close to the actual situation. Jianping Wang combined with EFDC model, WASP model and GIS system to study the Miyun Reservoir and its watershed nutrients, which are beneficial for managing Miyun reservoir, Yixin Yan studied the COD dynamics model of Yangtze River Estuary and got the distribution trend.

This study is based on the EFDC model, combined with historical monitoring data and on-site mapping tools, analysis hydrodynamic characteristics of river basins, using the observed data and EFDC model, to achieve a hydrodynamic water quality simulation and further study the dynamic environmental capacity of the basin.

\section{Research AREA AND WATER QuAlity Profile}

\section{A. Study Area}

Qingyi River rises in Xinzheng City ditch grass garden, from Changge into the territory of Xuchang, flows through Changge City, Xuchang County, Wei Du District (Xuchang City), Yanling County and Luohe City, Linying County, Import into Ying River from Yanling County.

Qingyi River is $149 \mathrm{~km}$ long(Fig. 1), watershed area is $2362 \mathrm{~km}^{2}$, accounting for nearly $32.1 \%$ Ying River Basin area .The total length of $79 \mathrm{~km}$ river basin area is $1585 \mathrm{~km}^{2}$ in Xuchang City, accounting for $67 \%$ of the area of Qingyi River Basin.

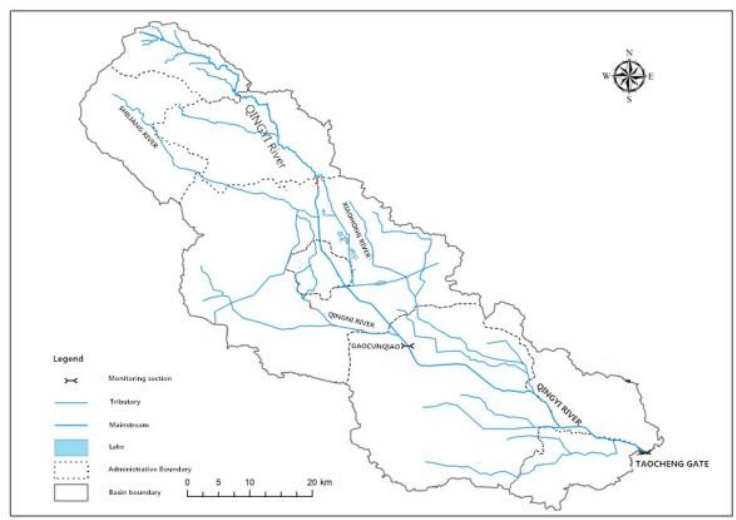

Fig. 1. Location of study area

\section{B. Water Quality}

As can be seen from Fig. 2, COD water quality trends are more stable from 2011 to 2013, the overall trend is 
decreasing year by year. The annual average data stand at $53.72 \mathrm{mg} / \mathrm{L}$ in 2011 and then the number plunged to $48.35 \mathrm{mg} / \mathrm{L}$ in 2013. The concentration of COD in 2012 and 2013 basically shows the low water quality in the wet season and the high water concentration in the dry season.

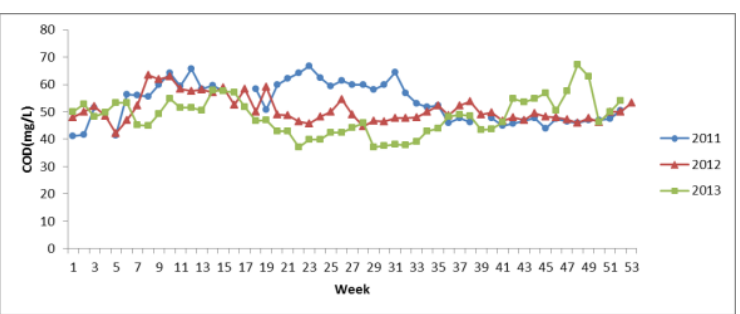

Fig. 2. Trend of COD concentration in Gaocun Bridge section from 2011 to 2013.

As can be seen from Fig. 3, ammonia nitrogen water quality changed dramatically from 2011 to 2013.The average annual concentrations of ammonia nitrogen in 2011 and 2013 were $2.21 \mathrm{mg} / \mathrm{L}$ and $2.57 \mathrm{mg} / \mathrm{L}$ respectively. In 2013, the concentration of ammonia nitrogen was higher, but the change trend in the three years was basically same. In the whole year, the concentration was relatively high in March-June, but lower in September-November.

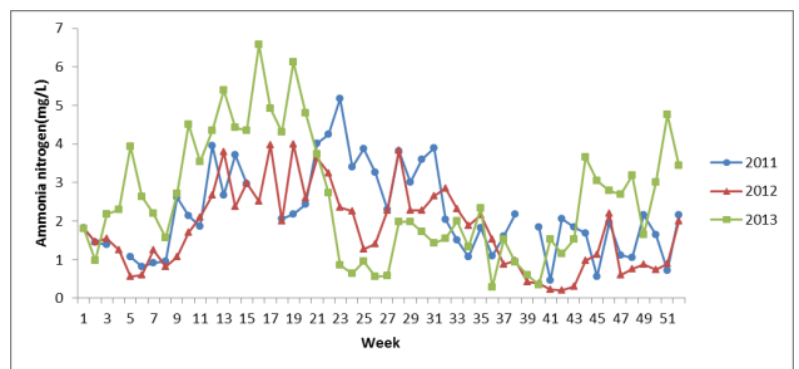

Fig. 3. Trend of ammonia nitrogen concentration in Gaocun Bridge section from 2011 to 2013

\section{RESEARCH METHODS AND DATA}

\section{A. Model Description}

Environmental hydrodynamic model EFDC is the United States Environmental Protection Agency (USEPA) recommended surface water dynamic water quality model. This model can be simulated the hydrodynamics and water quality of rivers, lakes, reservoirs, wetland systems, estuaries and oceans [4]-[8].

The EFDC model has three primary functional components including hydrodynamics (Fig. 4), water-quality-euthrophication, and sediment-toxic contaminant transport and fate, fully coupled and integrated into a single software system.

\section{B. Model Settings}

\section{1) River bottom terrain}

Data of the underwater topographic data used in the model are mainly the 23 points data obtained in the field survey in 2015. Due to we have no historical river bottom terrain monitoring data in Qingyi River Basin, let's say the river bottom elevation has not changed much in recently years.

\section{2) Grid resolution}

The generation of river grid is very important to hydrodynamic and water quality simulation [9]. EFDC model can identify rectangular grid and orthogonal curve mesh, but the natural water body waterfront geometric shape is often irregular. When we carry out numerical simulation, the rectangular grid model boundary can not match the actual boundary. However, orthogonal curve mesh can solve this problem, and it can be applied to the numerical calculation of complex flow field.

The research adopt Delft 3D model to generate the mesh of the Qingyi River, and the number of meshes generated is 694, as shown in the Fig. 5.

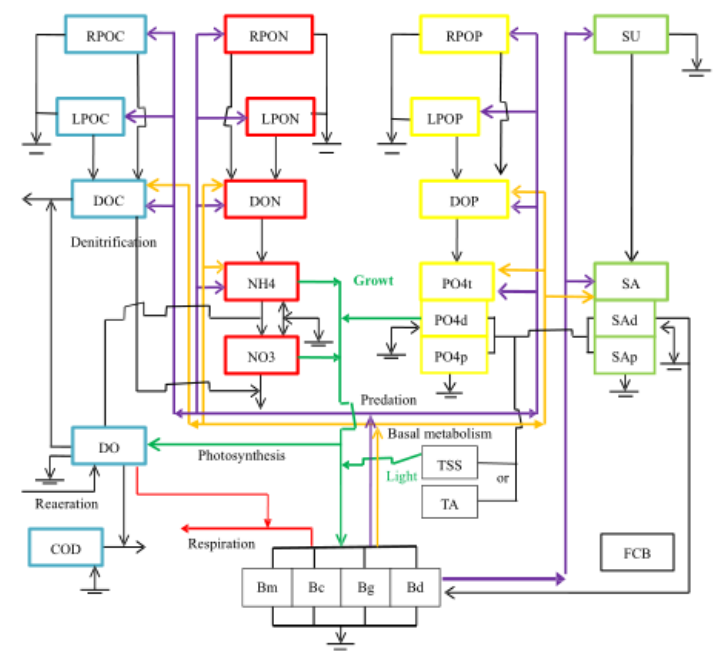

Fig. 4. Schematic diagram for the interactions of state variables of eutrophication model in the EFDC.

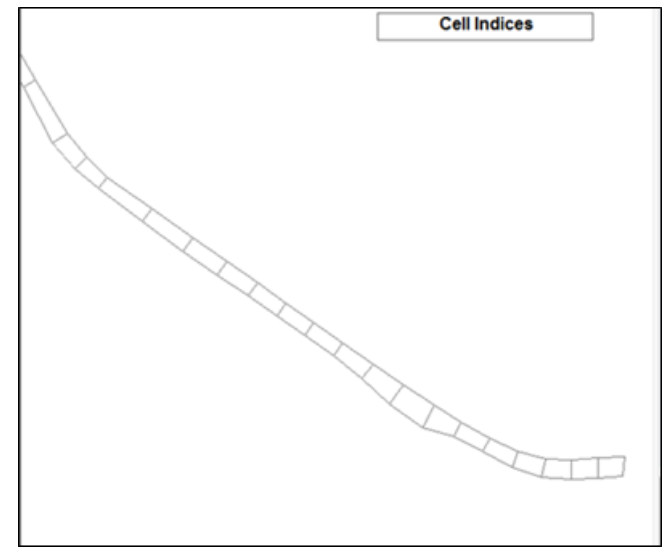

Fig. 5. The figure of Qingyi River grids (local)

\section{3) Boundary conditions}

Hydrodynamic model: Qingyi River Gaocun Bridge section and Linying Taocheng gate section of the flow has been monitored since the ecological compensation implemented in Qinghe River Basin from 2010. Weekly average flow data monitored from January to December 2013 are used during the build process.

Water quality model: During the water quality simulation, we chose the upper stream of Changge City Huangcun to Lin Ying Gaocun Bridge section. In setting the boundary of pollution sources, the daily average of pollution sources data from Xuchang City Environmental Monitoring Center to provide the daily average of pollution sources data from January-December 2013 has been referenced.

In this model $1.5 \mathrm{~m}$ was set to the initial water depth. The cold start mode was selected in this model. 


\section{4) Main parameters of the model}

The river bed roughness coefficient of the hydrodynamic model depends on the river type. The roughness of the Qingyi River Basin was set to 0.03 after reference to the roughness value of the plain natural river. The water quality model parameters $\mathrm{K}_{\mathrm{COD}}$ and $\mathrm{K}_{\mathrm{NH} 3-\mathrm{N}}$ were set to 0.15 and 0.15 .

\section{MOdEl RATE AND VERIFICATION}

Gaocun bridge section flow changes was simulated in January-December 2013, and compared with the measured flow in the same period to verify the rationality of the model. The results(Fig. 6) shows that the hydrodynamic simulation error of Qinghe River Basin is 30\%, the relative error of chemical oxygen demand of Gaocun bridge section(Fig. 7) is $13 \%$, ammonia nitrogen annual average relative error of simulation(Fig. 8) is $54 \%$, the overall simulation results are good.

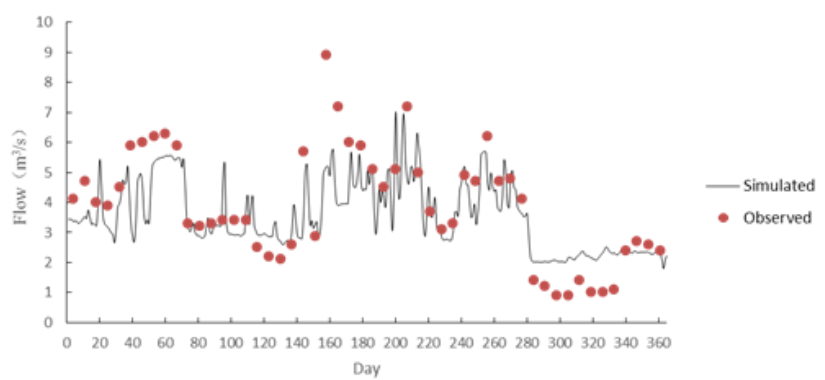

Fig. 6. Flow rate calibration and verification of Gaocun Bridge in Qingyi River.

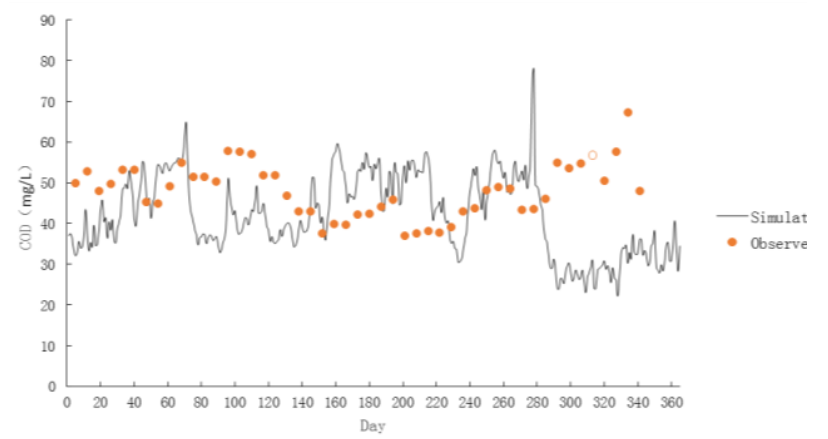

Fig. 7. COD rate and validation of Gaocun Bridge section.

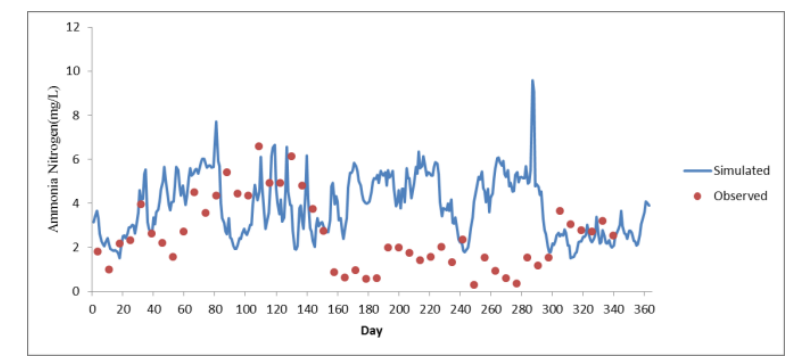

Fig. 8. Determination and verification of ammonia nitrogen in Gaocun Bridge section.

\section{STUDY ON DYNAMIC ENVIRONMENTAL CAPACITY}

\section{A. Calculation of Water Environment Capacity}

Water environment capacity has a relationship with water characteristics [10], [11], hydrological conditions, water quality objectives, pollutant characteristics and pollutant emissions and so on. For a given river, the environmental capacity will vary dynamically when hydrological conditions, water quality objectives, and pollutant emissions changes.

Considering the clear diffusion of the Qingyi River Basin in the horizontal direction, the environmental capacity was calculated on the basis of one-dimensional hydrodynamic water quality model as follow:

$$
W_{i}=31.54 *\left[\left(Q_{i}+q_{i}\right)^{*} C s i * e^{k x i / 86.4 * u i-} C_{i}^{*} Q_{i}\right]
$$

where $W_{i}$ is the environmental capacity, $Q_{i}$ is the river flow $\left(\mathrm{m}^{3} / \mathrm{s}\right), q_{i}$ is the wastewater into the river $\left(\mathrm{m}^{3} / \mathrm{s}\right), C_{s i}$ is the water quality standard for the ith river section $(\mathrm{mg} / \mathrm{L}), C_{i}$ is the water quality local concentration of the section above the ith section $\left(\mathrm{mg} / \mathrm{L}, u_{i}\right.$ is the design flow of the its section $(\mathrm{m} / \mathrm{s})$, $x_{i}$ is the distance of the $\mathrm{i}$-th $\operatorname{section}(\mathrm{km})$.

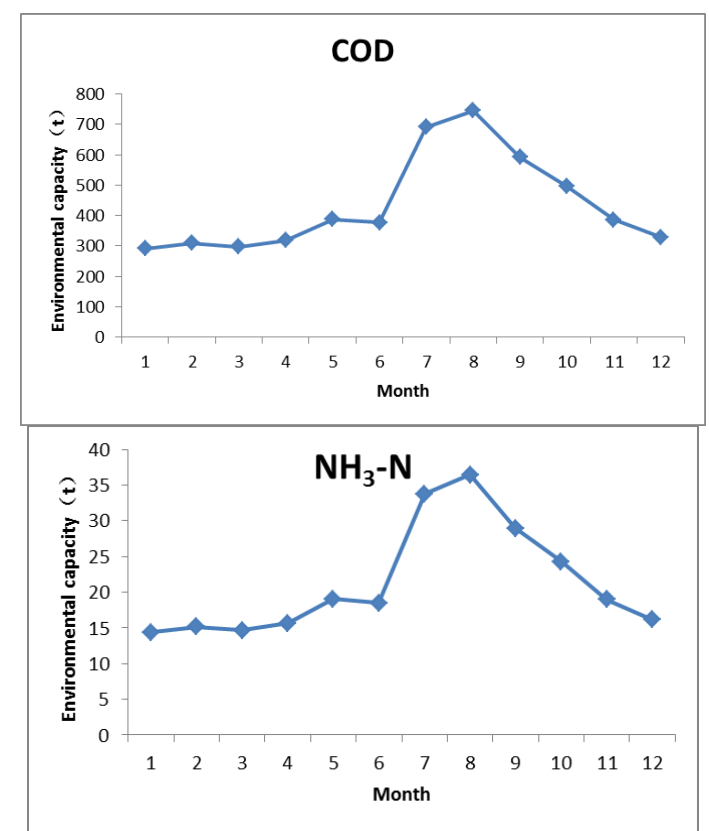

Fig. 9. Monthly environmental capacity of $\mathrm{COD}$ and $\mathrm{NH}_{3}-\mathrm{N}$ in Qingyi River Basin (class IV standard).

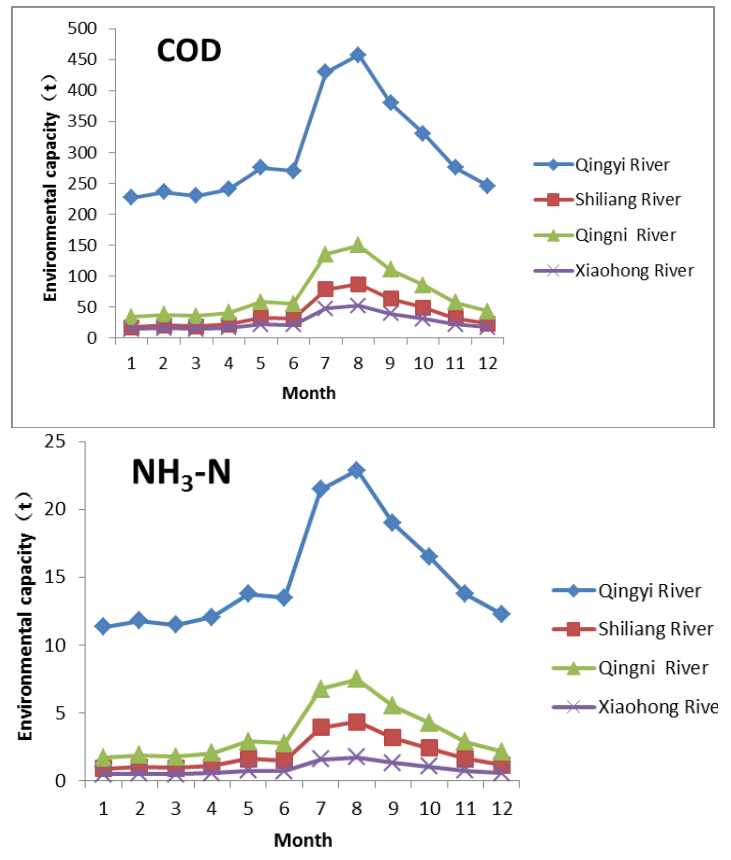

Fig. 10. Monthly average environmental capacity of main tributaries in Qingyi River Basin (class IV standard). 
The dynamic environmental capacity of COD and NH3-N in Qingyi River Basin was calculated by the calculation method of water environment capacity and design conditions.

As can be seen from Fig. 9, the monthly environmental capacity of COD and NH3-N in Qingyi River Basin shows highly in the wet season (June-September), with the environmental capacity for $746 \mathrm{t}$ and the ammonia nitrogen capacity for 36t. But the data declined sharply in Jan, which the environmental capacity of COD and ammonia nitrogen were $291 \mathrm{t}$ and $14 \mathrm{t}$ respectively.

As can be seen from Fig. 10 that the environmental capacity of the Qingyi River in Qingyi River Basin is the largest, and the environmental capacity in the three main tributaries is Qingnihe River> Shiliang River> Xiaohong River in Qingyi River, The COD and NH3-N environmental capacity of main stream are respectively $68 \%$ and $70 \%$ of the total drainage area.

\section{CONCLUSIONS}

1) In this paper, the one-dimensional hydrodynamic model of Qingyi River is established by EFDC model. The results of model validation are relatively good.

2) The monthly average dynamic environmental capacity of Qingyi River and its main tributaries are calculated, and the monthly environmental capacity of COD and NH3-N of Qingyi River Basin is simulated by the standard of Class IV water.

3) Among the tributaries of Qingyi River, the order of environmental capacity shows Qingniyi River> Shiliang River> Xiaohong River.

4) Through the research on COD and NH3-N monthly environmental capacity in Qingyi River Basin, it can support the total pollutant control in the basin, and make full use of the environmental capacity of river basin.

\section{REFERENCES}

[1] Y. Yang, X. N. Yin, and Z. F. Yang, "Environmental flow management strategies based on the integration of water quantity, a case study of the Baiyangdian Wetland, China," Ecolgogical Engineering, 2015.

[2] J. J. Liu, S. Q. Qi, Y. W. Zhang, and L. H. Wan, "Establishment of hydrodynamic model for main stream river network in Harbin segment of Songhua River and its application in urban flood early warning and prevention decision making," Journal of Natural Disasters, vol. 24, no. $2,2015$.

[3] Y. L. Zhu, Z. X. Xu, G. Q. Wang, W. D. Yu, and S. H. C. Tian, "Hydrodynamic modeling in ungauged rivers: A case study in the Wei river," Journal of Beijing Normal University (Natural Science), 2010, vol. 46 , no. 3 .

[4] A. Shakibaeinia, S. Kashyap, Y. B. Dibike, and T. D. Prowse, "An integrated numerical framework for water quality modeling in cold-region rivers: A case of the lower Athabasca River."

[5] S. Jeong, K. Yeon, Y. Hur, and K. Oh, "Salinity intrusion characteristics analysis using EFDC model in the downstream of Geum River," Journal of Environmental Sciences, vol. 22, no. 6, pp. 934-939, 2010.

[6] M. B. Liu, Hydrodynamic and Water Quality Modeling for the Lower Reaches of Minjiang River, Fujian Normal University, 2006.

[7] L. B. Chen, Z. F. Yang, H. F. Liu, "Assessing the eutrophication risk of the Danjiangkou Reservoir based on the EFDC model".

[8] J. C. Huang, R. H. Yan, J. F. Gao, Z. M. Zhang, and L. Y. Qi, "Modeling the impacts of water transfer on water transport pattern in Lake Chao, China," Ecological Engineering, vol. 95, 2016, pp. 271-279.
[9] G. Z. Wu and Z. X. Xu, "Prediction of algal blooming using EFDC model: Case study in the Daoxiang Lake," Ecological Modelling, vol. 222, pp. 1245-1252, 2011.

[10] S. F. Ge, "Study on water environmental capacity of Liaohe River in Jilin province," Jilin University, 2012.

[11] Z. H. Wei et al., "Modeling study of dynamic environmental capacity of Erhai Lake," Ecological Science, vol. 32, no. 3, pp. 282-289, 2013.

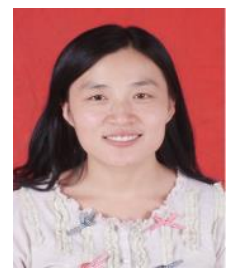

Yanpeng Wang was born in Xinmi, Henan province, in 1984. She studied from professor $\mathrm{Lu} \mathrm{Ji} \mathrm{Yu}$ in 2007-2010, and obtained a master's degree in environmental engineering from the College of Water Conservancy and Environment, Zhengzhou University in 2010. Since graduating in 2010, she has been engaged in environmental economics policy, environmental planning and management related research in environmental policy planning and assessment of Zhengzhou University.

As a key technical staff to complete the "Henan province, ecological compensation and pollution compensation key technology research", "Environmental capacity of the right to use price formation mechanism and key technology research" which results have been adopted by the Henan Provincial Environmental Protection Department ; 2013 July - 2014 July, as the main technical backbone of the successful application of the national major water projects, "The Qingyi River Basin water quality improvement and functional recovery of key technology integration research and integrated demonstration project" (2015ZX07204-002); currently involved or responsible for the research topic in the country (2013ZX07603004-005), "Henan Province, the basin water pollution automatic monitoring and management system", "Xuchang City thirteenth five environmental protection plan" and so on.

She won the 2012 scientific and technological progress prize three (the main completion of the first four people) for "Henan province watershed ecological compensation and pollution compensation key technology research", "environmental capacity utilization price formation mechanism and key technology research" in 2015 was identified as The leading domestic level (the main completion of the first four people), published five papers in the domestic core academic journals published five papers, one being edited monographs.

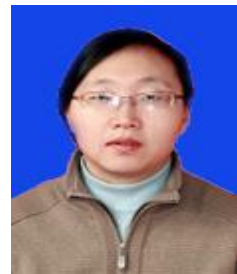

Li Wang was born in 1973. She is senior engineer of Zhengzhou University. She is mainly engaged in environmental science and engineering research and teaching. The main research directions is the water pollution control, water ecological restoration theory and technology, environmental policy planning.

She won the second prize of scientific and technological progress in Henan Province, a third prize, to participate in the publication of a monograph, published more than 20 professional papers, 2 patents. She participated in drafting the "Henan Province Paper Industry Water Pollutant Discharge Standard", participated in the completion of the "Eleventh Five-Year" Water Project 10 Huaihe River Basin water pollution control and control decision support key technology research and integrated management platform construction (topic number: 2008ZX07010- 010), presided over the study of the "12th Five-Year" water special Qing River (Xuchang segment) multi-objective multi-sectoral integrated management decision-making platform and water environment functional recovery comprehensive demonstration (sub topic number: 2015ZX07210-002-005), involved in research Research and Demonstration on Key Technologies of Aquatic Ecological Restoration in the Huaihe River Basin in the 12th Five - Year Plan Period (Project No.: 2012ZX07204-004).

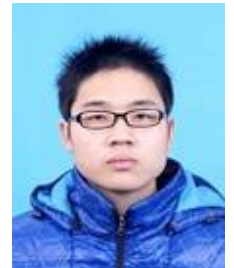

Kuan Zhang was borned in Fengqiu, Henan province, in 1991. He graduated from Northeastern University in Shenyang, China in 2014, with a master's degree in engineering. The major of study is environmental engineering.

$\mathrm{He}$ is now working in the Research Center for Environmental Policy Planning and Assessment of Zhengzhou University from September2014. The main research directions are the water environment model, water pollution control etc. He has completed the research work of water pollution automatic monitoring management system of Henan Province, mainly bear the EFDC model development. 